\title{
BMJ Open Prevalence and coprevalence of chronic comorbid conditions in patients with type 2 diabetes in Catalonia: a population-based cross-sectional study
}

\author{
Manel Mata-Cases, ${ }^{1,2}$ Josep Franch-Nadal, ${ }^{1,2}$ Jordi Real, ${ }^{1,2}$ Marta Cedenilla, ${ }^{3}$ \\ Didac Mauricio 2,4
}

To cite: Mata-Cases M, Franch-Nadal J, Real J, et al. Prevalence and coprevalence of chronic comorbid conditions in patients with type 2 diabetes in Catalonia: a population-based cross-sectional study. BMJ Open 2019;9:e031281. doi:10.1136/ bmjopen-2019-031281

- Prepublication history and additional material for this paper are available online. To view these files, please visit the journal online (http://dx.doi org/10.1136/bmjopen-2019031281).

Received 25 April 2019 Revised 29 August 2019 Accepted 17 September 2019

Check for updates

(C) Author(s) (or their employer(s)) 2019. Re-use permitted under CC BY-NC. No commercial re-use. See rights and permissions. Published by BMJ.

${ }^{1}$ DAP-Cat Group. Unitat de Suport a la Recerca Barcelona Ciutat, Institut Universitari d'Investigació en Atenció Primària Jordi Gol (IDIAP Jordi Gol), Barcelona, Spain

${ }^{2}$ CIBER of Diabetes and Associated Metabolic Diseases (CIBERDEM), Instituto de Salud Carlos III (ISCIII), Barcelona, Spain

${ }^{3}$ Medical Affairs, Merk Sharp \& Dohme Spain, Madrid, Spain

${ }^{4}$ Department of Endocrinology

\& Nutrition, Hospital de la Santa Creu i Sant Pau, Barcelona, Spain

Correspondence to

Dr Didac Mauricio;

didacmauricio@gmail.com

\section{ABSTRACT}

Objectives To evaluate the prevalence and coprevalence of several chronic conditions in patients with type 2 diabetes in a Mediterranean region.

Design A cross-sectional study.

Setting Two hundred and eighty-six primary care teams of the Catalonian Health Institute (Catalonia, Spain).

Participants We included patients aged $\geq 18$ years with a diagnosis of type 2 diabetes by 31 December, 2016, who were registered in the Information System for the Development of Research in primary care (SIDIAP) database. We excluded patients with a diagnosis of type 1 diabetes, gestational diabetes mellitus and any other type of diabetes.

Primary and secondary outcome measures We collected data on diabetes-related comorbidities (ie, chronic complications, associated cardiovascular risk factors and treatment complications). Diagnoses were based on the International Classification of Diseases, $10^{\text {th }}$ Revision codes recorded in the database or, for some entities, on the cut-off points for a particular test result or a specific treatment indicated for that entity. The presence and stage of chronic kidney disease (CKD) were based on the glomerular filtration rate, the CKD Epidemiology Collaboration creatinine equation and the urine albuminto-creatinine ratio.

Results A total of 373185 patients were analysed. $82 \%$ of patients exhibited $\geq 2$ comorbidities and $31 \%$ exhibited $\geq 4$ comorbidities. The most frequent comorbidities were hypertension $(72 \%)$, hyperlipidaemia $(60 \%)$, obesity (45\%), CKD (33\%), chronic renal failure (CRF) (28\%) and cardiovascular disease (23\%). The most frequently coprevalent pairs of chronic conditions were the combination of hypertension with hyperlipidaemia ( $45 \%)$, obesity ( $35 \%)$, CKD $(28 \%)$, CRF $(25 \%)$ or cardiovascular disease (19\%), as well as the combination of hyperlipidaemia with obesity (28\%), CKD (21\%), CRF (18\%) or cardiovascular disease (15\%); other common pairs of comorbidities were obesity/CKD, obesity/CRF, hypertension/ retinopathy, hypertension/albuminuria, hypertension/urinary tract infection, CVD/CRF and CVD/CKD, which were each present in more than $10 \%$ of patients.

Conclusion Patients with type 2 diabetes have a high frequency of coprevalence of metabolic risk factors, cardiovascular disease and CKD and thus require an integrated management approach.
Strengths and limitations of this study

- Population-based design.

- Use of a primary care registry with a large number of subjects managed under real world conditions.

- Unlike other population-based studies, the glycatedhaemoglobin levels and the glomerular filtration rate were available for approximately $90 \%$ of cases.

- Diagnoses were based on data recorded in the database. Therefore, a misclassification cannot be excluded.

- For some outcomes (eg, albuminuria), the proportion of missing data was high. Some laboratory data might have been available because the patients were at higher risk of developing particular conditions; therefore, our study may have overestimated the prevalence of diagnoses based on those laboratory values.

\section{INTRODUCTION}

Multimorbidity is common, ${ }^{12}$ and diabetes is the most common chronic comorbid condition among patients with multimorbidity after hypertension. ${ }^{3}$ The proportion of patients with diabetes who exhibit two or more chronic conditions exceeds $90 \%$ in studies conducted in the USA ${ }^{4-6}$ and Spain, ${ }^{7}$ reaches $75 \%$ in a study conducted in the $\mathrm{UK}^{8}$ and is over $50 \%$ in a study conducted in the Gulf countries. ${ }^{9}$ When evaluated individually, the most common comorbidities are hypertension, overweight/obesity, hyperlipidaemia, chronic kidney disease and cardiovascular disease. ${ }^{45}$ When evaluated in terms of the coprevalence of two or more chronic conditions, the most common doublets or triplets of comorbidities are concordant diseases (ie, diseases that are more directly related to the pathophysiological risk profile and/or management of diabetes). ${ }^{410-13}$

The presence of certain comorbidities in patients with diabetes may interfere with 
the achievement of therapeutic goals. Thus, the co-occurrence of obesity is associated with poorer glycaemic and blood pressure control ${ }^{1114}$ and a higher likelihood of emergency department visits and readmissions ${ }^{11}$; the co-occurrence of congestive heart failure correlates with the lack of achievement of cholesterol management. ${ }^{14}$ Comorbidities in patients with diabetes also negatively impact quality of life and the ability to self-manage the disease, and they increase healthcare utilisation. ${ }^{12}$ 15-17 Certain comorbidities, such as macrovascular disease, chronic respiratory disease and chronic kidney disease, are associated with an increased risk of mortality. ${ }^{18}$ Nevertheless, the appropriate management of multimorbidity in patients with diabetes can lead to more effective disease management and, in turn, improve patient outcomes. ${ }^{10}$

Although some studies have evaluated the prevalence and coprevalence of chronic comorbid conditions in patients with diabetes, most were conducted in the USA, and few studies have been conducted in Europe. ${ }^{3781920}$ Of these studies, two used non-representative convenience samples, ${ }^{19} 20$ and one was conducted in a Mediterranean region (Basque Country, Spain $)^{7}$; however, this latter study does not include information on important comorbidities such as obesity, hyperlipidaemia and chronic kidney disease. Additionally, information on drug therapy among these patients is scarce. ${ }^{21}$

In the present study, we aimed to evaluate the prevalence and coprevalence of several chronic conditions in patients with type 2 diabetes in a Mediterranean region (Catalonia, Spain) using the Information System for the Development of Research in primary care (SIDIAP) database. We also aimed to specifically study the prevalence and coprevalence of cardiovascular diseases and chronic kidney disease (distinguishing between chronic kidney disease and chronic renal failure) in this population. Finally, we evaluated the use of oral antihyperglycaemic drugs in these patients.

\section{PATIENTS AND METHODS}

\section{Study design, data sources and selection criteria}

This cross-sectional study used the SIDIAP database, which has been described in detail elsewhere. ${ }^{22}{ }^{23}$ Healthcare is organised in Spain in the framework of a National Health System that is mainly financed by general taxes and based on the principles of universality, free access and equity. People are assigned to a family physician and a nurse practitioner (basic unit of care) who are working together in geographically organised primary healthcare teams. The Catalonian Health Institute is the main provider of primary healthcare services in Catalonia, managing 286 primary care teams, including $74 \%$ of the total population. Primary care professionals of the Catalonian Health Institute (approximately 15000 ) use the same computerised medical record programme (e-CAP) that was created and managed by the institution itself. The SIDIAP database was created in 2010 for research purposes and contains anonymous, longitudinal, patient information extracted from the e-CAP. Pharmacological treatments are automatically added to the SIDIAP from the pharmacy-invoicing data provided by the Catalonian National Health Service (CatSalut).

The study population consisted of patients aged at least 18 years with a diagnosis of type 2 diabetes mellitus (T2DM; International Classification of Diseases, $10^{\text {th }}$ Revision (ICD-10) codes E11, E11.0 to E11.9, E14 and E14.0 to E14.9) by 31 December, 2016. We excluded patients with a diagnosis of type 1 diabetes, gestational diabetes mellitus and any other type of diabetes.

In accordance with the Spanish regulations on observational studies, this retrospective study conducted using anonymised data did not require informed consent to be obtained from the patients. We did not involve patients or the public in our study.

\section{Patient and public involvement}

Patients were not involved in the design or conduct of the study. We plan to disseminate the results through peer-reviewed publications.

\section{Comorbidities and other patient and illness-related characteristics}

We collected data on comorbidities on 31 December, 2016, which was considered the index date. Based on a previous study, ${ }^{4}$ the following diabetes-related comorbidities (ie, chronic complications, associated cardiovascular risk factors and treatment adverse effects or contraindications) were recorded: congestive heart failure, chronic kidney disease, retinopathy, neuropathy, cardiovascular disease (myocardial infarction, ischaemic heart disease, cerebrovascular disease and peripheral arterial disease), urinary tract infection, genital mycotic infection, hypoglycaemia, pancreatitis, liver disease, hypertension, hyperlipidaemia, overweight/obesity, microalbuminuria and macroalbuminuria/proteinuria. Diagnoses were based on ICD-10 codes recorded in the database or, for some entities, on cut-off values for particular test results or a specific treatment indicated for that entity. Specific diagnosis codes and/or definitions appear in online supplementary table 1 .

In addition to comorbidities, the following information was recorded: age; gender; smoking status; time since the onset of T2DM; date of the T2DM diagnosis; the most recent values (closest to the index date) for systolic and diastolic blood pressure, total cholesterol, low density lipoprotein (LDL) cholesterol, high density lipoprotein (HDL) cholesterol, triglycerides, non-HDL cholesterol, weight, height, urine albumin-to-creatinine ratio (UACR), and glycated haemoglobin (HbAlc); the highest serum creatinine lab value (worst clinical situation) recorded in 2016; the use of antidiabetic agents coded with the Anatomical Therapeutic and Chemical Classification system; date of initiation of antidiabetic drugs; use of antihypertensive drugs and lipid-lowering agents; use of cardiovascular drugs and use of other treatments. The presence and stage of chronic kidney 
disease were based on the estimated glomerular filtration rate calculated using the Chronic Kidney Disease Epidemiology Collaboration (CKD-EPI) ${ }^{24}$ equation and the UACR. Microalbuminuria was defined as a UACR of 30 to $299 \mathrm{mg} / \mathrm{g}$, and macroalbuminuria was defined as a UACR $\geq 300 \mathrm{mg} / \mathrm{g}$. Chronic kidney disease (CKD) was defined as an estimated glomerular filtration rate $<60 \mathrm{~mL} / \mathrm{min} / 1.73 \mathrm{~m}^{2}$ calculated by using the CKD-EPI equation and/or urine UACR $\geq 30 \mathrm{mg} / \mathrm{g}$, while chronic renal failure (CRF) was defined as an estimated glomerular filtration rate $<60 \mathrm{~mL} / \mathrm{min} / 1.73 \mathrm{~m}^{2}$ calculated using the CKD-EPI equation. The inclusion of the CKD definition was based on the recommendation of the Kidney Disease: Improving Global Outcomes guidelines as a more comprehensive method to establish CKD staging.

\section{Statistical analysis}

Continuous variables are presented as the means and SD, and categorical outcomes variables are presented as absolute and relative frequencies.

We estimated the prevalence of individual conditions and the coprevalence of doublets of comorbid conditions, and these values are presented as the proportion of patients exhibiting the condition or doublet of conditions.

As preplanned, the presented prevalence and coprevalence results were stratified by sex and age. We estimated the proportion of patients who had an HbAlc level $<7.0 \%$ in groups stratified by the presence of comorbidities in target organs (ie, cardiovascular disease, heart failure, chronic kidney disease, neuropathy and retinopathy) and by the number of concurrent comorbidities in target organs to explore the potential relationship between the presence of comorbidities and the degree of diabetes control.

All statistical analyses were performed using Stata 15 (Stata Corp, College Station, Texas, USA).

\section{RESULTS}

\section{Patients' disposition and characteristics}

By 31 December, 2016, the SIDIAP database contained records from 7251277 patients; 373185 (5.1\%) met the inclusion criteria and were included in the analyses (online supplementary figure 1 ). The mean (SD) age of the patients was 70.3 (12.1) years (37\% were aged $\geq 75$ years), and the population contained a slightly higher percentage of men (55\%) (table 1). Forty-five per cent of the patients were obese, and $56 \%$ showed an HbA1c level lower than $7 \%$ (table 1 ). The most common treatments received were non-insulin antidiabetic drugs, either as monotherapy $(37 \%)$ or in combination $(23 \%)$.

\section{Prevalence of chronic comorbidities}

The mean (SD) number of comorbidities was 2.8 (1.4), with $82 \%$ of patients exhibiting two or more comorbidities and $31 \%$ exhibiting four or more comorbidities. Females showed a greater number of comorbidities than males $(33 \%$ and $29 \%$ of women and men, respectively, exhibited four or more comorbidities). Patients aged $\geq 75$ years also showed a greater number of comorbidities than younger patients $(41 \%$ of patients aged $\geq 75$ years had four or more comorbidities compared with $24 \%$ of patients aged $<75$ years).

The most frequent comorbidities were hypertension $(72 \%)$, hyperlipidaemia $(60 \%)$, obesity $(45 \%)$, chronic kidney disease $(33 \%)$, chronic renal failure $(28 \%)$ and cardiovascular disease (23\%) (figure 1). The pattern of comorbidities was similar between the two age groups, but patients aged $\geq 75$ years showed an increased frequency of hypertension, chronic kidney disease and chronic renal failure and, to a lesser extent, urinary tract infection and congestive heart failure; in contrast, the frequency of obesity was lower in this subgroup of patients (figure 2). Males and females showed a similar pattern of comorbidities, with females showing a greater frequency of urinary tract infection, obesity, chronic renal failure, hypertension and neuropathy, while males showed a greater frequency of cardiovascular disease (figure 3).

\section{Coprevalence of chronic comorbidities}

The most frequently coprevalent pairs of chronic conditions were the combinations of hypertension with hyperlipidaemia (45\%), obesity (35\%), chronic kidney disease (28\%), chronic renal failure $(25 \%)$ or cardiovascular disease $(19 \%)$, as well as the combinations of hyperlipidaemia with obesity (28\%), chronic kidney disease (21\%), chronic renal failure $(18 \%)$ or cardiovascular disease $(15 \%)$. Other common doublets of comorbidities were obesity and chronic kidney disease, obesity and chronic renal failure, hypertension and retinopathy, hypertension and albuminuria, hypertension and urinary tract infection, cardiovascular disease and chronic renal failure and cardiovascular disease and chronic kidney disease, which were each present in greater than $10 \%$ of patients (figure 4). This pattern of comorbidities was similar in patients aged $\geq 75$ years but, overall, with a higher prevalence than the values described above (online supplementary table 2). The pattern of the prevalence of doublets of chronic conditions was similar between males and females, except for a higher frequency of the combination of obesity with chronic kidney disease and hypertension with urinary tract infections in females, which were each present in $16 \%$ of patients (online supplementary tables 3,4$)$.

\section{Cardiovascular disease and chronic renal failure}

The proportions of patients presenting cardiovascular disease and chronic renal failure alone or in combination are shown in figure 5. Both entities were present in $10 \%$ of the patients in the overall sample and $16 \%$ of patients aged $\geq 75$ years (figure 5 ). The distribution of chronic renal failure stages in patients with diabetes and cardiovascular disease in the total population and in groups stratified by age is presented in figure 6 . 
Table 1 Patient characteristics

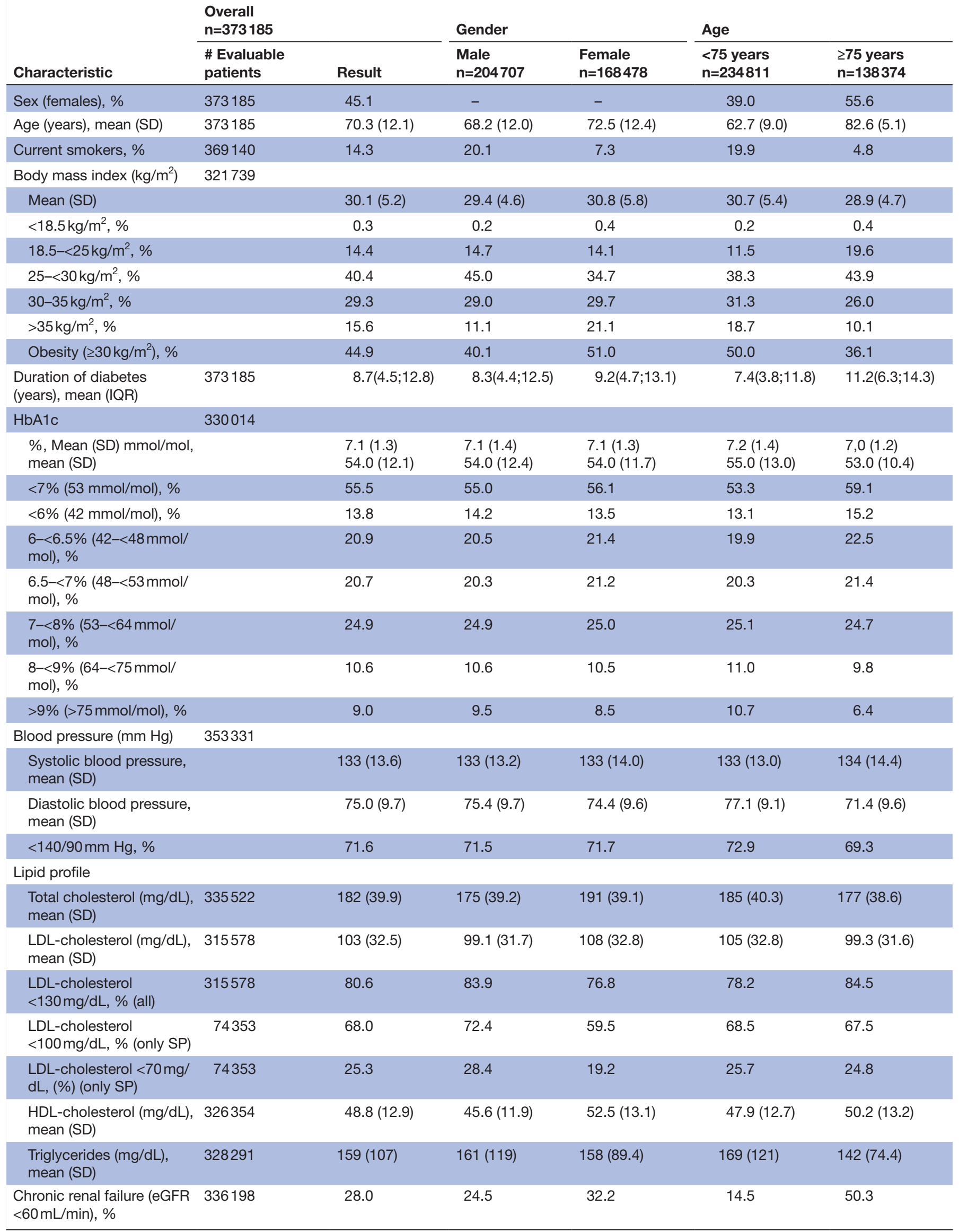


Table 1 Continued

\begin{tabular}{|c|c|c|c|c|c|c|}
\hline \multirow[b]{2}{*}{ Characteristic } & \multicolumn{2}{|l|}{$\begin{array}{l}\text { Overall } \\
\mathrm{n}=373185\end{array}$} & \multicolumn{2}{|l|}{ Gender } & \multicolumn{2}{|l|}{ Age } \\
\hline & $\begin{array}{l}\text { \# Evaluable } \\
\text { patients }\end{array}$ & Result & $\begin{array}{l}\text { Male } \\
\mathrm{n}=204707\end{array}$ & $\begin{array}{l}\text { Female } \\
n=168478\end{array}$ & $\begin{array}{l}<75 \text { years } \\
\mathrm{n}=234811\end{array}$ & $\begin{array}{l}\geq 75 \text { years } \\
\mathrm{n}=138374\end{array}$ \\
\hline $\begin{array}{l}\text { Severe chronic renal failure } \\
\text { (eGFR }<30 \mathrm{~mL} / \mathrm{min} \text { ), \% }\end{array}$ & 336198 & 3.9 & 3.4 & 4.6 & 1.7 & 7.6 \\
\hline $\begin{array}{l}\text { End stage renal failure } \\
\text { (eGFR }<15 \mathrm{~mL} / \mathrm{min}), \%\end{array}$ & 336198 & 0.7 & 0.7 & 0.6 & 0.5 & 1.0 \\
\hline Therapeutic step, $\%$ & 373185 & & & & & \\
\hline No drugs & & 18.4 & 17.9 & 19.0 & 17.8 & 19.4 \\
\hline NIAD monotherapy & & 37.1 & 36.7 & 37.6 & 36.7 & 37.9 \\
\hline NIADs in combination & & 23.2 & 25.1 & 20.9 & 25.3 & 19.7 \\
\hline
\end{tabular}

eGFR, estimated glomerular filtration rate; HbA1c, glycated haemoglobin; HDL, high-density lipoprotein; IQR, interquartile range; LDL, low-density lipoprotein; NIAD, non-insulin antidiabetic drug.

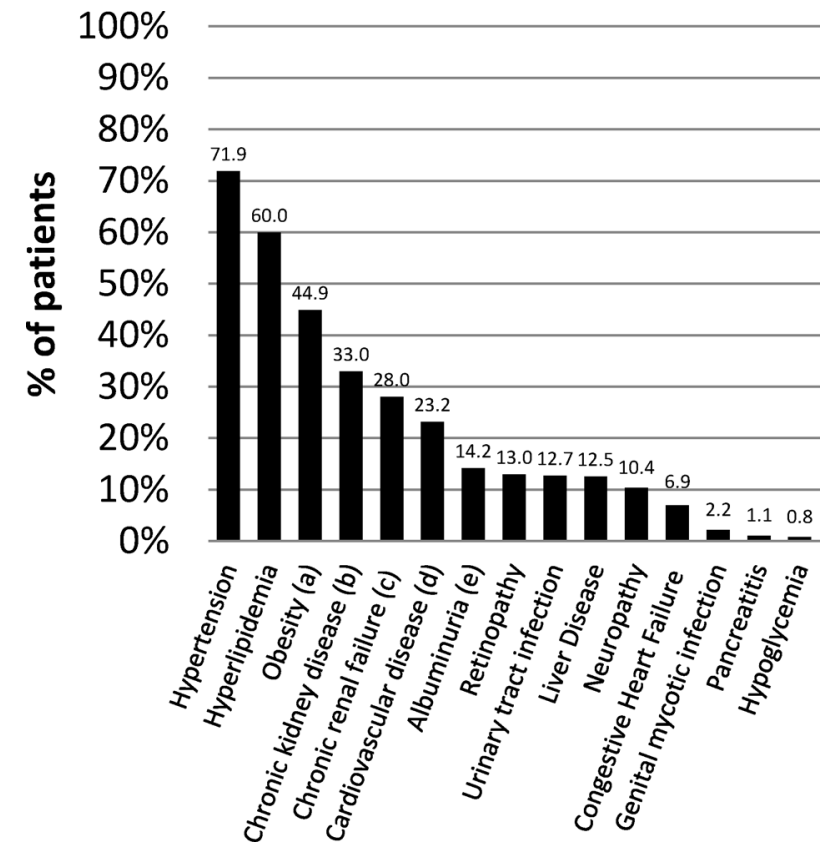

Figure 1 Prevalence of comorbidities in patients with type 2 diabetes in the total population. The proportions of patients with a particular comorbidity, regardless of the presence of other comorbidities are shown. (a) Obesity is defined as a body mass index $\geq 30 \mathrm{~kg} / \mathrm{m}^{2}$. (b) Chronic kidney disease is defined as an estimated glomerular filtration rate $<60 \mathrm{~mL} /$ $\mathrm{min} / 1.73 \mathrm{~m}^{2}$ calculated using the CKD-EPI equation and/or urine albumin-to-creatinine ratio $\geq 30 \mathrm{mg} / \mathrm{g}$. (c) Chronic renal failure is defined as an estimated glomerular filtration rate $<60 \mathrm{~mL} / \mathrm{min} / 1.73 \mathrm{~m}^{2}$ calculated using the CKD-EPI equation. (d) Cardiovascular disease included myocardial infarction, ischaemic heart disease, cerebrovascular disease and peripheral arterial disease. (e) Albuminuria is defined as a urine albumin-to-creatinine ratio $\geq 30 \mathrm{mg} / \mathrm{g}$. CKD-EPI,Chronic Kidney Disease Epidemiology Collaboration.

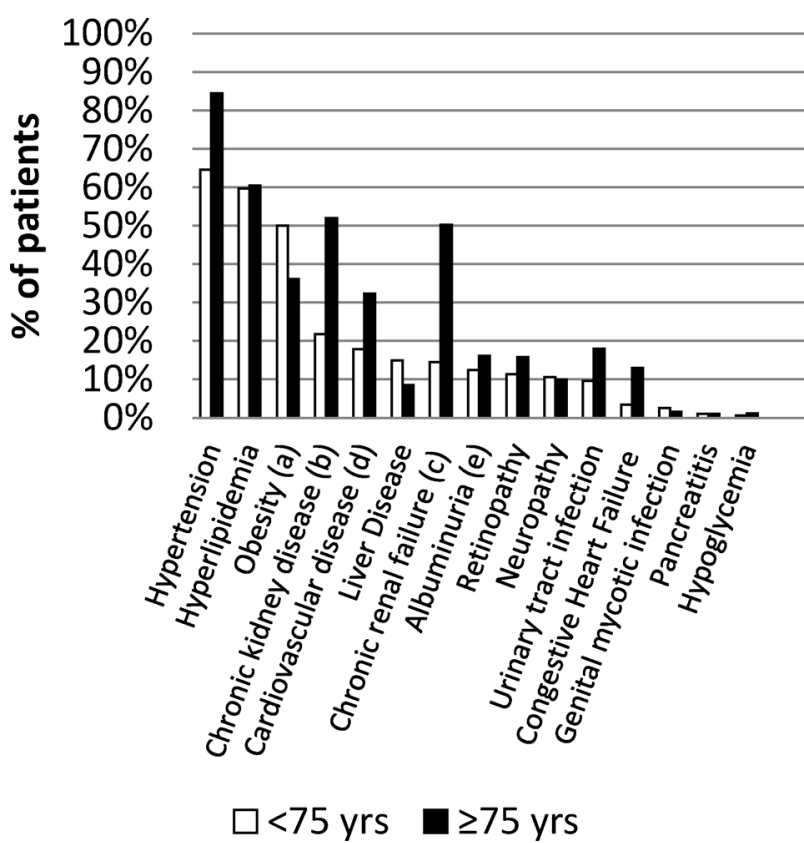

Figure 2 Prevalence of comorbidities in patients with type 2 diabetes stratified by age. The proportions of patients with a particular comorbidity, regardless of the presence of other comorbidities are shown. (a) Obesity is defined as a body mass index $\geq 30 \mathrm{~kg} / \mathrm{m}^{2}$. (b) Chronic kidney disease is defined as an estimated glomerular filtration rate $<60 \mathrm{~mL} /$ $\mathrm{min} / 1.73 \mathrm{~m}^{2}$ calculated using the CKD-EPI equation and/or urine albumin-to-creatinine ratio $\geq 30 \mathrm{mg} / \mathrm{g}$. (c) Chronic renal failure is defined as an estimated glomerular filtration rate $<60 \mathrm{~mL} / \mathrm{min} / 1.73 \mathrm{~m}^{2}$ calculated using the CKD-EPI equation. (d) Cardiovascular disease included myocardial infarction, ischaemic heart disease, cerebrovascular disease and peripheral arterial disease. (e) Albuminuria is defined as a urine albumin-to-creatinine ratio $\geq 30 \mathrm{mg} / \mathrm{g}$. CKD-EPI,Chronic Kidney Disease Epidemiology Collaboration. 

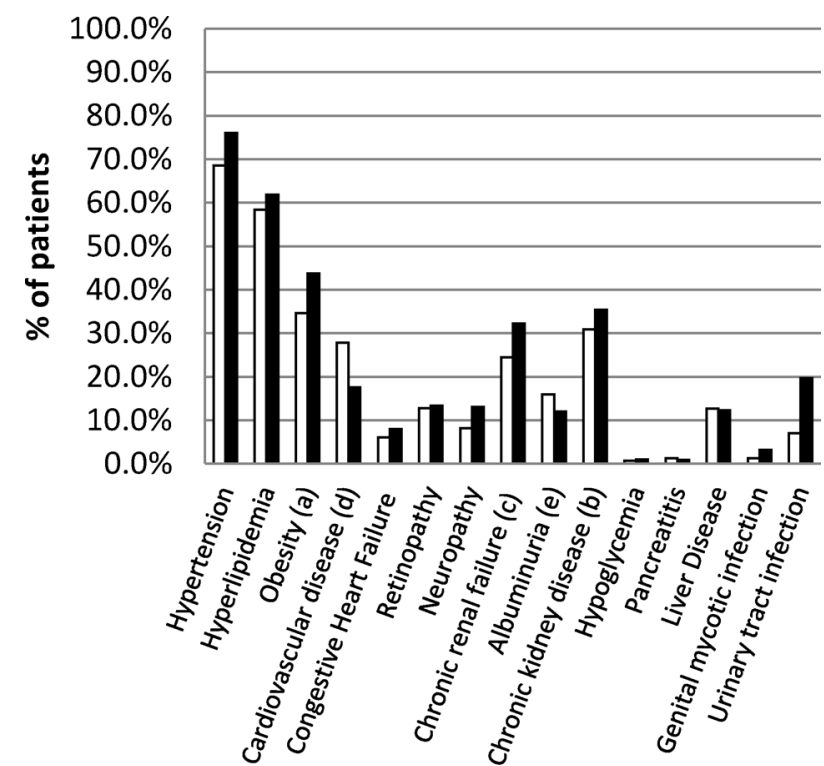

$\square$ Male $\square$ Female

Figure 3 Prevalence of comorbidities in patients with type 2 diabetes stratified by gender. The proportions of patients with a particular comorbidity, regardless of the presence of other comorbidities are shown. (a) Obesity is defined as a body mass index $\geq 30 \mathrm{~kg} / \mathrm{m}^{2}$. (b) Chronic kidney disease is defined as an estimated glomerular filtration rate $<60 \mathrm{~mL} /$ $\mathrm{min} / 1.73 \mathrm{~m}^{2}$ calculated using the CKD-EPI equation and/or urine albumin-to-creatinine ratio $\geq 30 \mathrm{mg} / \mathrm{g}$. (c) Chronic renal failure is defined as an estimated glomerular filtration rate $<60 \mathrm{~mL} / \mathrm{min} / 1.73 \mathrm{~m}^{2}$ calculated using the CKD-EPI equation. (d) Cardiovascular disease included myocardial infarction, ischaemic heart disease, cerebrovascular disease and peripheral arterial disease. (e) Albuminuria is defined as a urine albumin-to-creatinine ratio $\geq 30 \mathrm{mg} / \mathrm{g}$. CKD-EPI,Chronic Kidney Disease Epidemiology Collaboration.

\section{Comorbidities and glycaemic control}

Overall, $56 \%$ of the patients showed good glycaemic control. Glycaemic control was higher among patients who did not exhibit a comorbidity in a target organ, showing the greatest difference in patients without retinopathy compared with patients with retinopathy $(58 \%$ vs $42 \%$, respectively), who were considered to have good glycaemic control. The proportion of patients exhibiting good glycaemic control decreased as the number of comorbidities in target organs increased (59\%, 56\%, $52 \%$ and $44 \%$ for patients with $0,1,2$ and at least three comorbidities in target organs, respectively).

\section{DISCUSSION}

Patients with type 2 diabetes have a high prevalence of chronic comorbidities, particularly comorbidities related to diabetes, such as hypertension, hyperlipidaemia, obesity, chronic kidney disease, chronic renal failure and cardiovascular disease. These comorbidities also show a high coprevalence in these patients. The prevalence and coprevalence of chronic comorbidities in patients with type 2 diabetes increase with age.

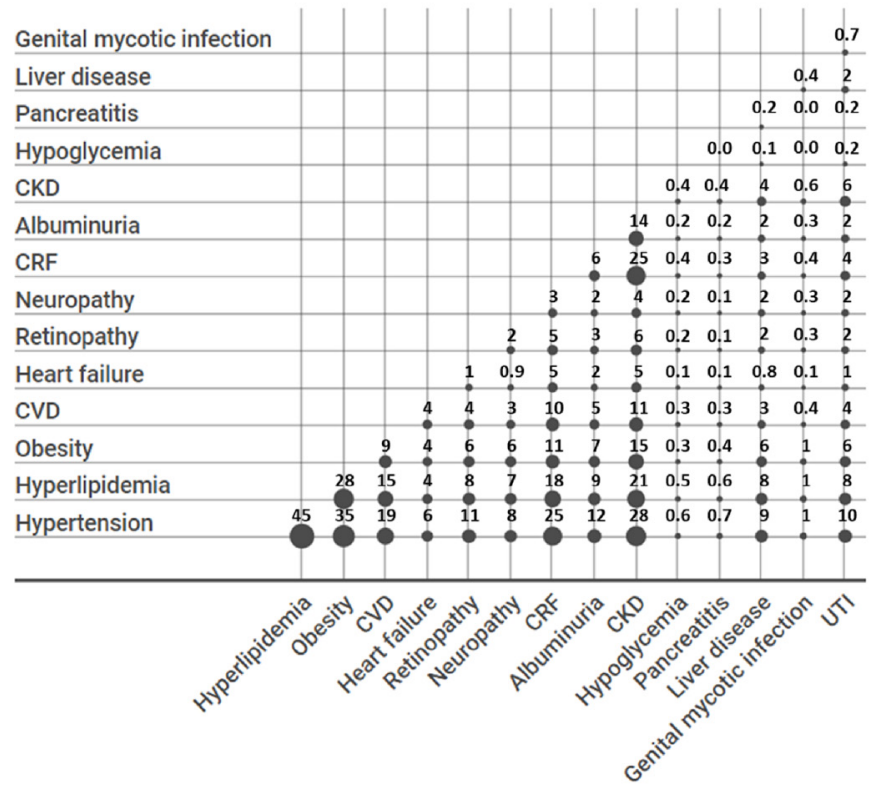

Figure 4 Coprevalence of medical conditions among patients with type 2 diabetes. All values are percentages and have been rounded off to the nearest whole number, except for values less than 1.0. CKD, chronic kidney disease; CRF, chronic renal failure; CVD, cardiovascular disease; UTI, urinary tract infection.

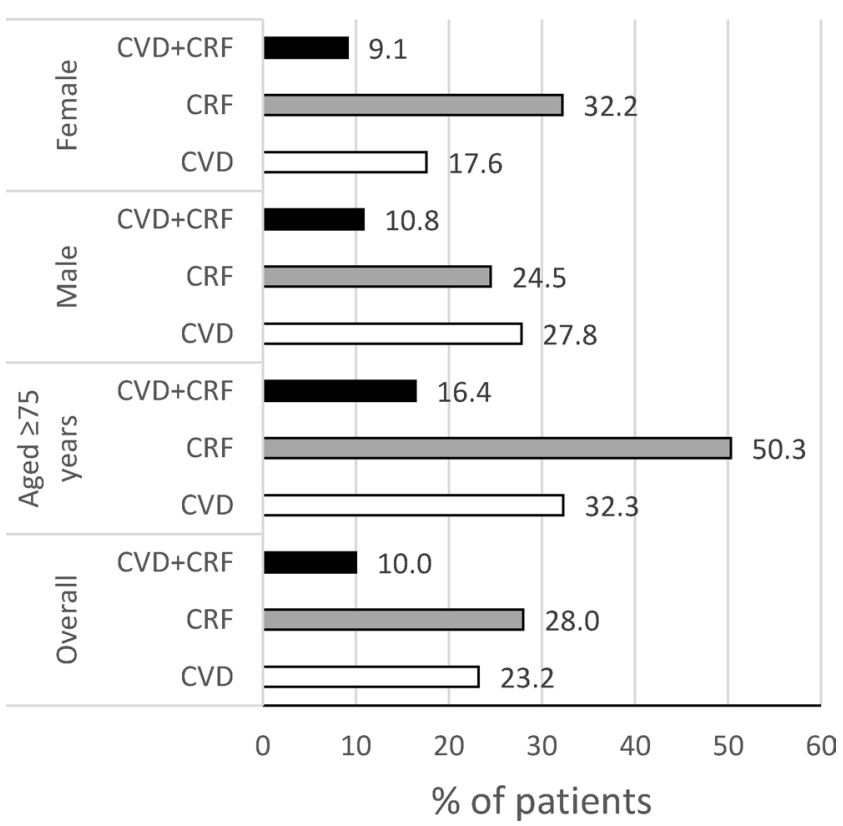

Figure 5 Frequency of cardiovascular disease, chronic renal failure and both medical conditions concomitantly in patients with type 2 diabetes. Note: Patients who presented both comorbidities, cardiovascular disease and chronic renal failure, are also included in the individual categories. CVD included myocardial infarction, ischaemic heart disease, cerebrovascular disease and peripheral arterial disease; CRF is defined as an estimated glomerular filtration rate $<60 \mathrm{~mL} /$ $\mathrm{min} / 1.73 \mathrm{~m}^{2}$ calculated using the CKD-EPI equation. CKD, chronic kidney disease; CKD-EPI, Chronic Kidney Disease Epidemiology Collaboration; CRF, chronic renal failure; CVD, cardiovasculardisease. 
100

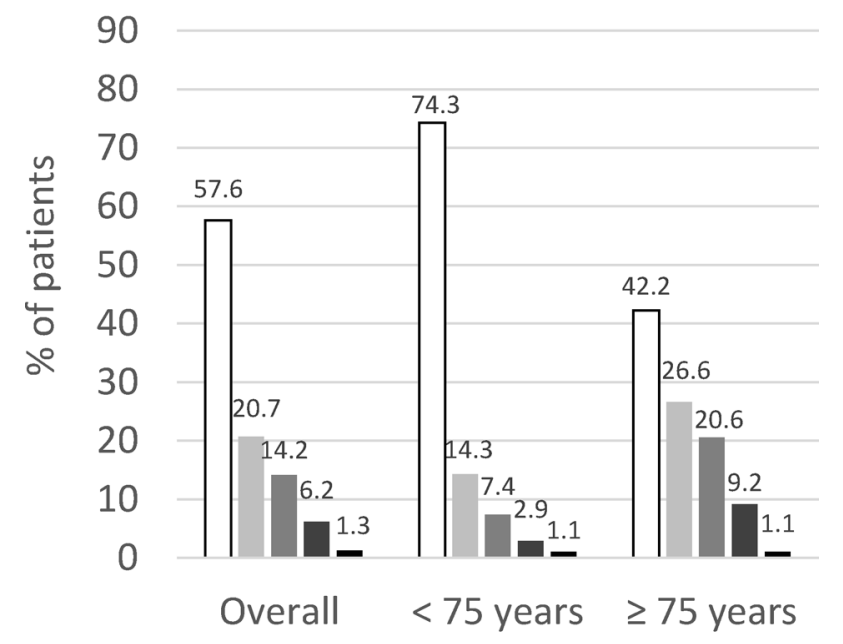

口eGFR > 60 eGFR: 45-59 " eGFR: 30-44

eGFR: $15-29$ eGFR <15

Figure 6 Distribution of chronic renal failure stages in patients with type 2 diabetes and cardiovascular disease. eGFR, estimated glomerular filtration rate.

A high proportion (31\%) of patients had four or more comorbidities, increasing to $41 \%$ in patients aged $\geq 75$ years. Consistent results were reported by Iglay et al, who found that $49 \%$ of patients with T2DM aged 75 years or older exhibited four or more chronic comorbidities in a study using a similar design with a larger database in the USA. ${ }^{4}$ In contrast to their results, we observed a higher prevalence of comorbidities among women; however, in our study, women were 4 years older than men. Meanwhile, in the study by Iglay et $a l$, women were slightly younger than men. The most frequent comorbidities were hypertension (72\%), hyperlipidaemia $(60 \%)$, obesity (45\%), chronic kidney disease (33\%), chronic renal failure $(28 \%)$ and cardiovascular disease $(23 \%)$. Iglay et al reported a higher prevalence of hypertension $(82 \%)$, overweight/obesity $(78 \%)$ and hyperlipidaemia $(77 \%)$, a lower prevalence of chronic kidney disease $(24 \%)$ and a similar prevalence of cardiovascular disease $(22 \%) .{ }^{4}$ Differences in the prevalence values between our results and the study by Iglay et al may be explained by the differences in the characteristics of the populations from the USA and Spain, for instance, in the prevalence of obesity ( $38 \%$ and $18 \%$ for the USA and Spain, respectively $^{25}$ ). Other studies conducted in various settings have provided similar results, except for the results for chronic kidney disease, with a high frequency of hypertension, metabolic disorders and cardiovascular disease. ${ }^{12} 1920$ Chronic kidney disease appears underrepresented in the other studies because the authors did not include a definition based on the actual laboratory values but instead relied on the recorded diagnosis.

The most frequent pairs of coprevalent disorders in our study were the combination of hypertension and hyperlipidaemia and the combinations of both hypertension and hyperlipidaemia with obesity, cardiovascular disease and chronic kidney disease. For the individual comorbidities, the pattern reported in our study is similar to patterns described in previous studies in the USA using information from primary care physicians, ${ }^{4}$ from a health informatics company ${ }^{11}$ or from the databases of the Veteran Administration and Medicare. ${ }^{13}$ The pattern is also similar to the pattern reported in a population-based study conducted in Ontario (Canada) ${ }^{12}$ and a study conducted by the diabetes clinic of a university hospital in Belgium. ${ }^{19}$ The pattern observed in the subgroup of patients aged $\geq 75$ years is also similar to the overall sample, but the frequency of coprevalence of chronic kidney disease with other cardiovascular risk factors or cardiovascular disease increases substantially; thus, in this subgroup of patients, chronic kidney disease was coprevalent with hypertension in $47 \%$ of patients, with hyperlipidaemia in 32\%, with obesity in $20 \%$ and with cardiovascular disease in $19 \%$. These results are difficult to put into perspective with findings from other studies since the occurrence of chronic kidney disease was usually based on the presence of a diagnosis. However, in our study, chronic kidney disease was based on the actual laboratory values for creatinine or the urine albumin-to-creatinine ratio. For instance, in the study conducted by Steinman et al using the Veteran Administration and Medicare databases, chronic kidney disease (recorded in their study as chronic renal insufficiency) appears underrepresented, with less than $20 \%$ of the patients $\geq 75$ years old showing chronic renal failure. ${ }^{13}$ In our study, $50 \%$ of patients aged $\geq 75$ years presented this condition. The same issue and similar findings are applicable to the study by Lin et al, who observed a prevalence of chronic kidney disease of $9 \%$ in patients aged 65 years or older. ${ }^{11}$ Using the same definition of chronic kidney disease in patients from a diabetic clinic of a hospital in Belgium, Hermans and Dath identified a $46 \%$ prevalence of this condition; unfortunately, in this latter study, the results were not stratified by age, and only data for the most frequent coprevalent comorbidities were reported. $^{19}$

Other doublets of frequent coprevalent comorbidities in our study were obesity and chronic kidney disease, cardiovascular disease and chronic kidney disease, hypertension and retinopathy and hypertension and urinary tract infection. The coprevalence of obesity and chronic kidney disease and of hypertension and retinopathy in patients with diabetes is well supported by the literature. Hypertension is an important factor contributing to the occurrence and progression of diabetic retinopathy, ${ }^{26} 27$ and tight control of blood pressure reduces the risk of complications of this condition. ${ }^{28}$ Obesity is a risk factor for developing chronic kidney disease, even in patients without metabolic disease. ${ }^{29}$

Chronic kidney disease and diabetes are risk factors for cardiovascular diseases; therefore, comorbidity among these three clinical conditions is frequent. ${ }^{30}$ Importantly, the presence of chronic kidney disease and/or cardiovascular disease is important in the selection of 
antihyperglycaemic treatment. ${ }^{31}{ }^{32}$ In clinical practice, a substantial proportion of patients with diabetes received medications or doses that should be avoided in patients with these comorbid conditions. ${ }^{33-35}$ In fact, new treatment guidelines from the American Diabetes Association/European Association for the Study of Diabetes for the management of type 2 diabetes consider the presence of cardiovascular disease and chronic renal failure as key elements for the selection of second-line treatment. ${ }^{36}$ This problem increases in very old patients; thus, $50 \%$ of patients $\geq 75$ years old had chronic renal failure, as evaluated with the estimated glomerular filtration rate, greater than $30 \%$ had cardiovascular disease, and approximately $16 \%$ exhibited both conditions in the present study. Finally, fewer studies have examined the relationship between hypertension and urinary tract infection in patients with diabetes. Patients with diabetes appear to be at increased risk of urinary tract infection compared with healthy controls, and this comorbidity also appears to be associated with renal damage. ${ }^{37}$ In a descriptive study conducted in 1000 patients with diabetes, one-quarter had a urinary tract infection, and the factors associated with the presence of this condition were hypertension, insulin therapy and nephropathy ${ }^{38}$; our results are consistent with these findings.

Our study has several limitations. We only included certain comorbidities; therefore, our results only reflect a snapshot of diabetes-related comorbidities. Since most of our diagnoses were based on data recorded in the database, a misclassification cannot be excluded. However, the validity of the SIDIAP database for studying the prevalence of cardiovascular risk factors has been confirmed in a previous study ${ }^{39}$ For some outcomes, the proportion of missing data was high, such as albuminuria with $38 \%$ missing data. The relevant data may have been available for patients because the laboratory test was requested by their physicians due to the suspicion of their being at a greater risk of developing those conditions; therefore, our study may have overestimated the prevalence of diagnoses based on those laboratory values. The strengths of our study include a population-based design, the use of a primary care registry with a large number of subjects managed under real world conditions and, unlike other population-based studies, including previous studies from our group analysing the SIDIAP database, the HbAlc levels and glomerular filtration rates were available for approximately $90 \%$ of patients.

\section{CONCLUSIONS}

Consistent with previous studies, our findings show that patients with diabetes have a high frequency of coprevalent metabolic risk factors, cardiovascular disease and chronic kidney disease. These findings again highlight the importance of implementing an integrated approach for managing all these conditions since they are responsible for a substantial proportion of the burden of diabetes, ${ }^{11} 121516$ and their combined effects are responsible, to a great extent, for their mortality. ${ }^{40}$

Acknowledgements This study was possible through the commitment of physicians and nurses working in the Catalan Health Institute who provide care to patients with diabetes. CIBER of Diabetes and Associated Metabolic Diseases (CIBERDEM) is an initiative from Instituto de Salud Carlos III, Madrid, Spain. The authors thank Antón Gómez, Karine Ferreira and Gonzalo Fernández (Merck Sharp \& Dohme Spain) for their input on different aspects of the study design and analysis, and Fernando Rico-Villademoros (COCIENTE S.L., Madrid, Spain) for providing medical writing assistance.

Contributors MM-C, JF-N and DM contributed to the study design. JR was involved in data management and statistical analyses. MM-C wrote the first draft of the manuscript. MM-C, JF-N, JR, MC and DM contributed to the analysis and interpretation of the data, provided critical input during the development of the manuscript and approved the final version for submission. MM-C had full access to all data in the study and takes responsibility for the integrity of data and the accuracy of the data analysis.

Funding This study was supported by the Institut Universitari d'Investigació en Atenció Primària Jordi Gol (IDIAP Jordi Gol), and partially funded and sponsored by Merck Sharp \& Dohme Spain.

Competing interests $\mathrm{MM}-\mathrm{C}$ has received advisory honoraria from Astra-Zeneca, Bayer, Boehringer Ingelheim, GSK, Lilly, MSD, NOVARTIS, NovoNordisk and Sanofi. He has received speaker honoraria from Astra-Zeneca, Bayer, Boehringer Ingelheim, GSK, Lilly, Menarini, MSD, Novartis, NovoNordisk and Sanofi. He has received research grants to the institution from Astra-Zeneca, GSK, Lilly, MSD, Novartis, NovoNordisk and Sanofi. He has received research grants from Institut Universitari d'Investigació en Atenció Primària Jordi Gol (IDIAP Jordi Gol)(Barcelona, Spain), Instituto de Salud Carlos III (Madrid, Spain), Generalitat de Catalunya, Peris 20162020 and The Strategic Plan for Health Research and Innovation (Barcelona, Spain) Josep Franch-Nadal has received advisory and or speaking fees from Astra-Zeneca, Ascensia, Boehringer Ingelheim, GSK, Lilly, MSD, Novartis, NovoNordisk and Sanofi; he has received research grants to the institution from Astra-Zeneca, GSK, Lilly, MSD, Novartis, NovoNordisk, Sanofi and Boehringer. Jordi Real has no conflict of interest to declare. Marta Cedenilla is full-time employee of Merck Sharp \& Dohme Spain.Dídac Mauricio has received advisory and or speaking fees from AstraZeneca, Ascensia, Boehringer Ingelheim, GSK, Lilly, MSD, Novartis, NovoNordisk and Sanofi; he has received research grants to the institution from Astra-Zeneca, GSK, Lilly, MSD, Novartis, NovoNordisk, Sanofi and Boehringer.

\section{Patient consent for publication Not required.}

Ethics approval The study was approved by the Ethics Committee of the Primary Healthcare University Research Institute (IDIAP) Jordi Gol (Barcelona, Spain).

Provenance and peer review Not commissioned; externally peer reviewed.

Data availability statement Data are available upon reasonable request.

Open access This is an open access article distributed in accordance with the Creative Commons Attribution Non Commercial (CC BY-NC 4.0) license, which permits others to distribute, remix, adapt, build upon this work non-commercially, and license their derivative works on different terms, provided the original work is properly cited, appropriate credit is given, any changes made indicated, and the use is non-commercial. See: http://creativecommons.org/licenses/by-nc/4.0/.

\section{REFERENCES}

1 Buttorff C, Ruder T. Multiple chronic conditions in the United States. Santa Monica, CA: RAND Coorporation, 2017.

2 Heide vander I, Snoeijs S, Melchiorre MG, et al. Innovating care for people with multiple chronic conditions in Europe. NIVEL (Netherlands Institute for Health Services Research): Utrecht, 2015.

3 Hopman P, Heins MJ, Korevaar JC, et al. Health care utilization of patients with multiple chronic diseases in the Netherlands: differences and underlying factors. Eur J Intern Med 2016;35:44-50.

4 Iglay K, Hannachi H, Joseph Howie P, et al. Prevalence and coprevalence of comorbidities among patients with type 2 diabetes mellitus. Curr Med Res Opin 2016;32:1243-52.

5 An J, Le QA, Dang T. Association between different types of comorbidity and disease burden in patients with diabetes. J Diabetes 2019;11:65-74

6 Lin P-J, Pope E, Zhou FL. Comorbidity type and health care costs in type 2 diabetes: a retrospective claims database analysis. Diabetes Ther 2018;9:1907-18. 
7 Alonso-Morán E, Orueta JF, Fraile Esteban JI, Esteban JIF, et al. The prevalence of diabetes-related complications and multimorbidity in the population with type 2 diabetes mellitus in the Basque country. BMC Public Health 2014:14:1059.

8 Nowakowska M, Zghebi SS, Ashcroft DM, et al. The comorbidity burden of type 2 diabetes mellitus: patterns, clusters and predictions from a large English primary care cohort. BMC Med 2019;17:145.

9 Morgan SA, Ali MM, Channon AA, et al. Prevalence and correlates of diabetes and its comorbidities in four Gulf cooperation Council countries: evidence from the world health survey plus. J Epidemiol Community Health 2019;73:630-6.

10 Piette JD, Kerr EA. The impact of comorbid chronic conditions on diabetes care. Diabetes Care 2006;29:725-31.

11 Lin P-J, Kent DM, Winn A, et al. Multiple chronic conditions in type 2 diabetes mellitus: prevalence and consequences. Am J Manag Care 2015;21:e23-34.

12 Gruneir A, Markle-Reid M, Fisher K, et al. Comorbidity burden and health services use in community-living older adults with diabetes mellitus: a retrospective cohort study. Can J Diabetes 2016;40:35-42.

13 Steinman MA, Lee SJ, John Boscardin W, et al. Patterns of multimorbidity in elderly veterans. J Am Geriatr Soc 2012;60:1872-80.

14 Magnan EM, Palta M, Mahoney JE, et al. The relationship of individual comorbid chronic conditions to diabetes care quality. $B M J$ Open Diabetes Res Care 2015;3:e000080.

15 Kerr EA, Heisler M, Krein SL, et al. Beyond comorbidity counts: how do comorbidity type and severity influence diabetes patients' treatment priorities and self-management? J Gen Intern Med 2007;22:1635-40.

16 Beverly EA, Wray LA, Chiu CJ, et al. Perceived challenges and priorities in co-morbidity management of older patients with type 2 diabetes. Diabet Med 2011;28:781-4.

17 Terauchi Y, Ozaki A, Zhao X, et al. Humanistic and economic burden of cardiovascular disease related comorbidities and hypoglycaemia among patients with type 2 diabetes in Japan. Diabetes Res Clin Pract 2019;149:115-25.

18 Yokomichi H, Nagai A, Hirata M, et al. Survival of macrovascular disease, chronic kidney disease, chronic respiratory disease, cancer and smoking in patients with type 2 diabetes: Biobank Japan cohort. J Epidemiol 2017;27:S98-106.

19 Hermans MP, Dath N. Prevalence and co-prevalence of comorbidities in Belgian patients with type 2 diabetes mellitus: a transversal, descriptive study. Acta Clin Belg 2018;73:68-74.

20 Teljeur C, Smith SM, Paul G, et al. Multimorbidity in a cohort of patients with type 2 diabetes. Eur J Gen Pract 2013;19:17-22.

21 Doos L, Roberts EO, Corp N, et al. Multi-Drug therapy in chronic condition multimorbidity: a systematic review. Fam Pract 2014;31:654-63.

22 Bolíbar B, Fina Avilés F, Morros R, et al. [SIDIAP database: electronic clinical records in primary care as a source of information for epidemiologic research]. Med Clin 2012;138:617-21.

23 Mata-Cases M, Franch-Nadal J, Real J, et al. Glycaemic control and antidiabetic treatment trends in primary care centres in patients with type 2 diabetes mellitus during 2007-2013 in Catalonia: a populationbased study. BMJ Open 2016;6:e012463.
24 Levey AS, Stevens LA, Schmid CH, et al. A new equation to estimate glomerular filtration rate. Ann Intern Med 2009;150:604-12.

25 Organisation for Economic Co-operation and Development. Obesity update 2017. Paris, France: OECD, 2017.

26 Yamazaki D, Hitomi H, Nishiyama A. Hypertension with diabetes mellitus complications. Hypertens Res 2018;41:147-56.

27 Wat N, Wong RL, Wong IY. Associations between diabetic retinopathy and systemic risk factors. Hong Kong Med J 2016;22:589-99.

28 Matthews DR, Stratton IM, Aldington SJ, et al. Risks of progression of retinopathy and vision loss related to tight blood pressure control in type 2 diabetes mellitus: UKPDS 69. Arch Ophthalmol 2004;122:1631-40.

29 Nehus E. Obesity and chronic kidney disease. Curr Opin Pediatr 2018;30:241-6.

30 Suckling R, Gallagher $\mathrm{H}$, disease Ckidney. Chronic kidney disease, diabetes mellitus and cardiovascular disease: risks and commonalities. J Ren Care 2012;38 Suppl 1:4-11.

31 American Diabetes Association. 8. Pharmacologic Approaches to Glycemic Treatment: Standards of Medical Care in Diabetes-2018. Diabetes Care 2018;41:S73-85.

32 Menéndez SA. Actualización del algoritmo de hiperglucemia 2017. Diabetes práctica 2017:57-60.

33 Patel PA, Liang L, Khazanie P, et al. Antihyperglycemic medication use among Medicare beneficiaries with heart failure, diabetes mellitus, and chronic kidney disease. Circ Heart Fail 2016;9:e002638.

34 Clemens KK, Liu K, Shariff S, et al. Secular trends in antihyperglycaemic medication prescriptions in older adults with diabetes and chronic kidney disease: 2004-2013. Diabetes Obes Metab 2016;18:607-14.

35 Huang H, Shetty S, Bauer E, et al. Concordance with prescribing information dosage recommendations for dipeptidyl-peptidase-4 inhibitors among type 2 diabetes mellitus patients with moderate to severe chronic kidney disease. Curr Med Res Opin 2018;34:1021-7.

36 Davies MJ, D'Alessio DA, Fradkin J, et al. Management of hyperglycemia in type 2 diabetes, 2018. A consensus report by the American diabetes association (ADA) and the European association for the study of diabetes (EASD). Diabetes Care 2018;41:2669-701.

37 Goswami R, Bal CS, Tejaswi S, et al. Prevalence of urinary tract infection and renal scars in patients with diabetes mellitus. Diabetes Res Clin Pract 2001;53:181-6.

38 Al-Rubeaan KA, Moharram O, Al-Naqeb D, et al. Prevalence of urinary tract infection and risk factors among Saudi patients with diabetes. World J Urol 2013;31:573-8.

39 Ramos R, Balló E, Marrugat J, et al. Validity for use in research on vascular diseases of the SIDIAP (information system for the development of research in primary care): the EMMA study. Rev Esp Cardiol 2012;65:29-37.

40 Global Burden of Metabolic Risk Factors for Chronic Diseases Collaboration. Cardiovascular disease, chronic kidney disease, and diabetes mortality burden of cardiometabolic risk factors from 1980 to 2010: a comparative risk assessment. Lancet Diabetes Endocrinol 2014;2:634-47. 